\title{
Experience Differentiation Strategy (1): Concepts of Consumer Experiences
}

\author{
Shin'ya Nagasawa ${ }^{1}$, Shinich Otsu ${ }^{1,2}$ \\ ${ }^{1}$ Graduate School of Commerce, Waseda University, Tokyo, Japan \\ ${ }^{2}$ IBM Japan, Ltd., Tokyo, Japan
}

Email address:

nagasawa@waseda.jp (S. Nagasawa)

\section{To cite this article:}

Shin'ya Nagasawa, Shinich Otsu. Experience Differentiation Strategy (1): Concepts of Consumer Experiences. Science Journal of Business and Management. Special Issue: Customer Experience Management/MarketingBranding. Vol. 3, No. 2-1, 2015, pp. 73-77.

doi: $10.11648 /$ j.sjbm.s.2015030201.20

\begin{abstract}
In a mature market like recent Japanese economy, "experiential marketing" has received attention as "differentiation strategy." In this paper, we investigate concepts of experiential marketing. The results show that 1) experiences are involved in obtaining, consuming, and disposing process of products, 2) experiences occurs in a situation consumer face, 3) experiences are behaviors and physiological/psychological effects. These understandings of experiences help us effectively use experiences as differentiation strategy. We have conducted case studies that focus on the representation of luxury in cosmetics design for both domestic and foreign products and compared them based on the theory of customer experience proposed by Bernd $\mathrm{H}$. Schmitt. In this study, we attempted to examine the representation of luxury in relation to cosmetics design, through the analysis of four brands using the customer experience framework as a basis for analysis. The three elements that are considered necessary for the representation of luxury in cosmetics design are as follows: (1) Brand image or company image that is easily identifiable. (2) Each element of design contains a story. (3) The design is innovative and has exclusivity. In terms of functionality and effect/efficacy, the options are without number. However, luxury cosmetics stand as absolute with irresistible appeal. Cosmetics are used on a daily basis to make women beautiful. Women also carry around makeup products in their purse, which may catch people's eyes. In light of this, the representation of luxury in a cosmetic design can be an extremely important element.
\end{abstract}

Keywords: Customer Experience, Consumer Experience, Differentiation Strategy

\section{Background and Purpose}

\subsection{Necessity of a Customer Experience Strategy}

Recent mature societies like Japan's have required differentiation strategies that are not based solely on the functions and benefits of a product. Onzo put forward four strategies to consider when entering mature markets where products are increasingly commoditized - a customer experience strategy, quality value strategy, category value strategy, and proprietary value (leader) strategy - of which the customer experience strategy has been cited as the major pillar of the four [1]. The customer experience strategy aims to establish a unique position for products and services in the minds of customers by focusing on consumer experiences with product/service consumption, and differentiating such experiences.

Kotler included experiences in ten areas that should be addressed by marketers (goods, services, experiences, events, persons, places, properties, organizations, information, and ideas), and pointed out that consumer experiences should also be covered by marketing [2]. Pine et al. argued that consumers encounter many experiences when they use a product and that such experiences have the potential for differentiation [3] and indicated that consumer experiences provide a factor for differentiation.

As described above, consumer experience is attracting increasingly more public attention as a factor for differentiation in marketing.

\subsection{First Challenge for Developing a Customer Experience Strategy}

The customer experience strategy aims to establish a unique position for products and services in the minds of customers 
by focusing on consumer experiences with product/service consumption, and differentiating such experiences.

The important factor for formulating and implementing a customer experience strategy is the notion of experience. But the notion of experience is complex, and its definition lacks uniformity, making the customer experience strategy difficult to comprehend.

\subsection{Purpose of This Article}

In considering the dilemma mentioned above, to improve the practicability of the customer experience strategy, this article aims to reorganize the notion of experience, particularly consumer experience as covered by marketing, and provide an easy-to-understand definition. Specifically, the authors will review preceding studies on marketing theory of consumer experience and consumer behavior theory and present a new definition of consumer experience. In addition, based on such definition, the authors will examine methodologies to integrate factors that create enhanced consumer experiences into products and services.

\section{Examination of Preceding Studies}

This chapter examines the characteristics underlying consumer experiences by analyzing the viewpoints of preceding studies.

\subsection{Experiential Aspects of Consumption as Indicated by Holbrook}

In marketing, Holbrook was the first researcher to indicate the importance of experiential aspects of consumption. He argued that previous studies on consumer behavior had been able to explain only part of consumer behavior because they had disregarded the experiential aspects of consumption, and pointed out the importance of experiential views [4]. He held that experiential views represented subjective understandings of consumption such as symbolic meaning, epicurean responses, and aesthetic senses. What Holbrook pointed out presented important viewpoints in that he considered consumption as consumers' subjective experiences. Ishii later termed the standpoint emphasizing the experiential aspects of consumption, which was first put forward by Holbrook, as "subjective experiential consumption theory" [5], and Horiuchi described consumer experience theory [6].

\subsection{Definition of Experience by Schmitt}

Influenced by Holbrook, Schmitt advocated experiential marketing, a type of marketing that emphasized consumer experiences. He defined consumer experiences as follows:

Experiences are private events that occur in response to some stimulation (e.g., as provided by marketing efforts before and after purchase) [7].

Schmitt defined experiences as private events that occur in response to external stimuli. Private events refer to personal, subjective events. The definition of experiences as private events shows that one characteristic of experiences is that they are something private (personal, subjective): an experience belongs specifically to the person having the experience. One particular person's experience belongs only to that person and no one else. Similar to Holbrook, Schmitt believed that experiences were subjective.

Schmitt also argued that experiences could be classified into different categories depending on their structure and the way they were processed. In this manner, experiences were divided into five strategic experiential modules (SEMs): SENSE (sensory experiences), FEEL (emotional experiences), THINK (cognitive experiences), ACT (behavior experiences), and RELATE (relational experiences).

Table 1. Strategic Experiential Modules(SEMs) Provided by B.H. Schmitt.

\begin{tabular}{ll}
\hline Module & Contents of Customer Experience \\
\hline SENSE & $\begin{array}{l}\text { Sensory experience value that appeals to the five senses } \\
\text { Emotional experience value that appeals to feelings and } \\
\text { moods } \\
\text { Intellectual experience value that appeals to creativity } \\
\text { and cognitive functions } \\
\text { BHINK }\end{array}$ \\
BChavioral experience value that appeals to physical \\
behavior and lifestyle \\
Relative experience value that appeals to confirmative \\
groups and cultural groups
\end{tabular}

Source: Authors' elaboration based on Schmitt [7].

The experiential marketing definition put forward by Schmitt made the most of these strategic experiential modules (SEMs) to focus on consumer experience [7][8].

Of these five SEMs, SENSE, FEEL, THINK, and RELATE can be classified as internal experiences (such as senses, feelings, curiosity, and feelings of being connected), and ACT as an external experience (such as behavior). Holbrook emphasized the emotional aspects of consumers when he put forward the experiential aspects of consumption, most of which corresponded to internal experiences such as FEEL. Schmitt, on the other hand, showed that another factor of experience is behavior (ACT), and this was new.

These internal and external experiences can also be analyzed from the viewpoint of behavioral science. This branch of learning holds that behavior can be classified into two categories: overt behavior (observable behavior such as speech, expression, lines of sight, and physical movements) and covert behavior (unobservable behavior that occurs from within the body and the mind such as consciousness, perception, recognition, memory, image, thought, feelings, and attitudes) [9]. Both overt and covert behavior can be constituents of one's experience. In general, behavior is often considered to refer to overt behavior. For this reason, in this article the authors call overt behavior as classified by behavioral science "behavior" and covert behavior "physiological and psychological activities" so that the two categories of behavior can be better understood.

Schmitt also mentioned the timing with which experiences occur and pointed out that experiences could occur in both occasions before and after purchase. The definition of consumer behavior can be used as a reference when considering the timing of experiences. Consumer behavior is 
defined as the activity engaged in when consumers obtain, consume, and dispose of products and services [10]. As explained above, consumption spans a certain period of time, stretching over three phases: obtaining, consuming, and disposing.

In relation to this definition of consumer behavior, Nagasawa also indicated that experiences include all acts related to the obtaining, consumption, and disposal of products [11]. The phrase "the process of obtaining, consuming, and disposing of products," describing Schmitt's idea of "occasions before and after purchase" in more detail, delineates the timing of experiences more appropriately.

\subsection{Subjectivity of Experiences as Analyzed by Ogilvy}

Ogilvy, on the other hand, indicated that experiences are determined by their subjectivity. The advertising executive, who advocated the industrial concept of experience industry, argued that experiences are characterized by their subjectively recognized vividness and intensity of an objective situation, event, or circumstance, and that situations, events, and circumstances may or may not deserve special mention to those who experience them subjectively [11].

As pointed out by Ogilvy, the environmental factors recognized directly and subjectively by consumers are also important factors of experiences. If they are called environmental factors, they cover too wide a range of factors, but if they are limited to the situations experienced directly by consumers, they more accurately describe factors underlying experiences.

\section{Theorization: A New Definition of Consumer Experience}

The previous chapter examined preceding studies on consumer experiences. This chapter explores the construction of a new definition for consumer experience based on the previously described studies.

With respect to the temporal span of experiences, characteristic 1 listed below can be drawn from both Schmitt's idea of "both before and after purchase" and consumer behavior theory.

Characteristic 1: Experiences occur in the process of obtaining, consuming, and disposing of products and services.

For example, when purchasing a car, experiences occur in all three phases: obtaining a car when visiting a dealer's shop and purchasing it, actually using the car, and disposing of the automobile by sending it to a scrapper.

Then, with respect to the subjective reaction of experiences, characteristic 2 listed below can be drawn from Schmitt's strategic experiential modules (SEMs) and notions of behavioral science.

Characteristic 2: Experiences include consumer behavior as well as physiological and psychological activities (activities from within the body and the mind).

Examples of the physiological and psychological activities mentioned here can include mouthwatering (physiological activity) when one sees a delicious-looking (psychological activity) cake made by a distinguished patissier. Together with behavior, physiological and psychological activities constitute factors of experiences.

Based on Ogilvy's concept of subjective situations, characteristic 3 listed below can be derived.

Characteristic 3: Experiences occur in various situations that surround consumers and that they directly experience.

Take the example of visiting an overcrowded Disneyland. Visiting Disneyland itself is an action. On the other hand, an overcrowded Disneyland represents an environmental factor, a situation experienced directly by consumers. The previous concept of strategic experiential modules (SEMs) focused on the consumer behavior as well as the physiological and psychological activities described in Characteristic 2. But that alone does not explain experiences sufficiently. Therefore, combining such factors with situations is what makes this article's proposition original.

If the three characteristics listed above are joined, consumer experiences can be defined as follows:

Consumer experience refers to consumer behavior as well as physiological and psychological activities in various situations that surround consumers and that they directly experience during the process of obtaining, consuming, and disposing of products and services.

This definition of consumer experiences is original and is being described for the first time in this article.

\section{Application to the Integration of Experience-Enhancing Factors into Products and Services}

When using this definition of consumer experiences to integrate factors that derive enhanced and differentiated consumer experiences into products and services, marketers can do so by considering the questions presented in the following three viewpoints:

Viewpoint 1: Which of the processes of obtaining, consuming, and disposing should they pay attention to when determining the timing of experiences?

Viewpoint 2: What situations should they assume?

Viewpoint 3: What behavior as well as physiological and psychological activities should they target?

\subsection{Viewpoint 1: Which of the Processes of Obtaining, Consuming, and Disposing Should They Pay Attention to When Determining the Timing of Experiences}

Viewpoint 1 offers three choices: paying attention to experiences in the phase of obtaining, paying attention to experiences in the phase of consuming, and paying attention to experiences in the phase of disposing. Marketers should pay closest attention to experiences in the phase of consuming because the experiences gained in the consumption of products are of greatest importance to the consumer. In general, it can be said that experiences of a product refers to those in the phase of its consumption. 
On the other hand, experiences also occur in the phase of obtaining and disposing and can be used as factors for differentiation. An example of marketing in which experiences in the phase of obtaining were enhanced is WACOAL DIA, a luxury brand of WACOAL. Under this brand, all underwear is tried on in opulent fitting rooms and purchased at the company's directly managed store along the Namiki Street in Ginza. These fitting rooms have to be reserved in advance, and customers spend an average of one-and-a-half hours trying on underwear. Mineral water is served halfway through the session, and customers are encouraged to take sufficient time to reflect, for example, while looking at magazines, on the merchandise offered in order to be satisfied with their decision on what to buy [12]. In the phase of obtaining (purchasing) underwear, WACOAL provides customers with special experiences that offer an element of surprise and a sense of superiority, thus differentiating its brand from others. WACOAL DIA is an example of marketing in which the company focuses on experiences in the phase of obtaining to enhance the attraction of its products.

In general, not much attention is currently paid to the phase of disposing. In the future, however, it is expected that providing special experiences in the phase of disposing will provide another opportunity for differentiation. One example of experiences being provided in the phase of disposing is trash boxes in parks, a project implemented by NIKE in Brazil. The American multinational corporation installed basketball hoops in trash boxes in the parks with a NIKE logo printed on them. By doing this, NIKE made throwing away trash a sport [13]. This is an example of making disposal experiences enjoyable. In this example, however, trash boxes are used as an advertising medium, a case that does not involve a particular product's phase of disposal. Providing special experiences in a particular product's phase of disposal is expected to offer an idea for differentiation in the future.

\subsection{Viewpoint 2: What Situations Should They Assume}

It is generally considered difficult to integrate experienceenhancing factors into situations that consumers directly experience. But marketers can do so to a certain extent. For example, Albirex Niigata had the intention of mobilizing 40,000 people because there was a stadium that accommodated 40,000 people, and distributed a large number of free admission tickets to prospective spectators [11]. As a result, the football club successfully created a situation that packed the stadium with 40,000 spectators in the first place. Then, this situation made watching the soccer game an attractive experience because of the enthusiasm local consumers felt while supporting the football club and the sense of solidarity invoked in a stadium filled with 40,000 other spectators. It created the special experience of supporting the football club enthusiastically and feeling unified with other spectators when watching its game. In this example, the club's marketers succeeded in maximizing customer experience by focusing all their efforts on creating a situation that can enhance consumer experiences, though a situation is essentially an uncontrollable factor. As described above, it is important to consider not only products and services but also situations experienced by consumers and integrate factors that enhance consumer experiences into the situations.

\subsection{Viewpoint 3: What Behavior as Well as Physiological and Psychological Activities Should They Target}

With respect to Viewpoint 3 "What behavior as well as physiological and psychological activities should they target?" Schmitt's strategic experiential modules (SEMs) provide a useful framework. Marketers can identify the target consumer behaviors and physiological and psychological activities by establishing which of the five SEMs is the aim. Schmitt's SEMs provide tools that allow marketers to classify consumer experiences and use them as components that constitute the goals and strategies of their marketing activities.

As discussed above, in order to improve customer experience, marketers should determine the appropriate timing of the targeting as well as the consumer behavior and physiological/psychological activities, and integrate factors enhancing customer experiences into situations for products and services being offered. This is what the basic policy for differentiation through consumer experiences means.

\section{Conclusion}

This article offers a new, more cohesive definition of consumer experience for which previous interpretations had often been divided among researchers. This article also shows that consumer experiences can be interpreted using three factors: (1) the processes of obtaining, consuming, and disposing of products and services, (2) situations that surround consumers and that are experienced directly by them, and (3) consumer behavior as well as physiological and psychological activities. In order to integrate factors that enhance and differentiate consumer experiences into products and services, it is important to take these three viewpoints into consideration. These ideas can help marketers better understand consumer experiences, use the viewpoints of consumer experiences, and implement customer experience strategies.

This article puts forward a novel definition and provides methodologies for consumer experiences and strategies. Further exploration of successful product or service examples should be addressed in the future.

\section{References}

[1] Onzo, N. (2007), Marketing Theory for Commoditization Markets, Yuhikaku Publishing, Tokyo (in Japanese).

[2] Kotler, P. and K.L. Keller (2006), Marketing Management (12th Ed), Prentice Hall, New Jersey.

[3] Pine II, B.J. and J.H. Gilmore (1999), The Experience Economy, Harvard Business School Press, Boston. 
[4] Holbrook, B.M. and E. Hirschmann (1982), "The Experimential Aspects of Consumption: Consumer Fantasies, Feelings and Fun," Journal of Consumer Research, September, Vol.9, pp.132-140.

[5] Ishii, J. (2004), The Myths of Marketing, Iwanami Gendai Bunko, Tokyo (in Japanese).

[6] Horiuchi, K. (2001), Studies of Epicurean Consumption, Hakuto-Shobo Publishing, Tokyo (in Japanese).

[7] Schmitt, B. H. (1999), Experiential Marketing: How to Get Customers to Sense, Feel, Think, Act, and Relate to Your Company and Brands, Free Press, Detroit.

[8] Schmitt, B. H. (2003), Customer Experience Management: A Revolutionary Approach to Connecting With Your Customers, John Wiley \& Sons, New Jersey.

[9] Maiya, K. and Y. Yonezawa, Y. (2001), An Introduction to Behavioral Science: Approaches of Contemporary Psychology, Fukumura Shuppan, Tokyo (in Japanese).
[10] Blackwell, R.D., P.W. Miniard, J.F. Engel (2006), Consumer Behavior 10th edition International Student Edition, Thomson South-Western, Mason.

[11] Nagasawa, S. ed., Waseda Business School Nagasawa Laboratory (2005), Creation of Customer Experiences That Bring Hit Products: Manufacturing That Excites the Kansei of Consumers, JUSE Press, Tokyo (in Japanese).

[12] Nagasawa, S. ed., Waseda Business School Nagasawa Laboratory (2007), Manufacturing for Customer Experiences: Brand Value and Creation of Situations to Produce Hit Products, JUSE Press, Tokyo (in Japanese).

[13] Sato, N. (2008), The Advertising of Tomorrow: Methods of Communication with Changing Consumers, ASCII. 